\title{
Can parents who smoke socialise their children against smoking? Results from the Smoke-free Kids intervention trial
}

\author{
C Jackson, D Dickinson
}

See end of article for authors' affiliations

\section{Correspondence to:} Christine Jackson, $\mathrm{PhD}$, Department of Health Behavior and Health

Education, School of Public Health, University of North Carolina at Chapel Hill, Chapel Hill, NC 27599-7400, USA chris_jackson@unc.edu

Received 28 June 2002. Accepted

18 December 2002

\begin{abstract}
Objective: To evaluate Smoke-free Kids, a new home based programme to assist parents who smoke in socialising their children against smoking.

Design: Two year randomised controlled trial.

Participants: At baseline, 887 adult smokers who had an abstinent child in the third grade lages 7-8 years); 671 adults and children were retained through the 24 month follow up.

Intervention: Programme modules, newsletters, incentives, support calls.

Outcomes: Anti-smoking socialisation; susceptibility to smoking.

Results: Of 327 parents randomised to treatment, 210 obtained adequate treatment by using at least three of five core modules. Programme efficacy analyses, which compared these parents with controls $(n=344)$, showed that exposure to adequate treatment predicted significantly higher levels in nearly all categories of anti-smoking socialisation three months post-intervention. Two years post-baseline, children of parents who reported adequate treatment scored significantly higher than controls on attributes that reduce susceptibility to smoking, and they scored significantly lower than controls on attributes that raise susceptibility to smoking. Programme effectiveness analyses compared all parents randomised to treatment $(n=327)$ with controls $(n=344)$. Treatment effects were evident for several socialisation outcomes; however, these effects were smaller and less consistent than those from the efficacy analyses. Similarly, although treated children scored higher than controls on attributes that reduce susceptibility and lower than controls on attributes that raise susceptibility, several of these between-group differences were not significant.

Conclusions: Given adequate exposure to the Smoke-free Kids programme, significant beneficial effects were observed on anti-smoking socialisation in households where parents smoke cigarettes, and significant beneficial effects were observed on children's susceptibility to smoking after two years. Improving programme acceptance and utilisation is necessary before programme effectiveness can be demonstrated.
\end{abstract}

$S$ noke-free Kids is an anti-smoking socialisation programme developed to assist parents who smoke in preventing their children from smoking. Key assumptions of the Smoke-free Kids intervention are that parents who smoke can undertake an array of anti-smoking socialisation activities and that exposure to anti-smoking socialisation can lower children's risk of smoking. This study assessed the effects of Smoke-free Kids on anti-smoking socialisation among parents three months post-intervention and it examined the effects of the programme on children's susceptibility to smoking two years post-baseline.

\section{Anti-smoking socialisation}

Research on socialisation indicates that parents are the primary socialising agents during childhood, and that siblings, peers, teachers, and environmental factors, such as mass media, are important but secondary agents. ${ }^{1-3}$ Thus, an early socialisation approach to smoking prevention requires strong parental involvement. A strong parental role can provide an obvious link to the home environment, but also has the potential, via programme guided activity, to modify children's exposure to, and interpretation of pro-smoking influences in the social environment.

Anti-smoking socialisation refers to parent-child interactions that influence the development of children's cognitive and behavioural norms regarding smoking. ${ }^{4-7}$ During the childhood years, through communication, rule setting, monitoring, guided experience, and other socialisation practices, parents can influence children's perceptions of the prevalence of smoking, of the acceptability of smoking, and of the personal and social consequences of smoking. Anti-smoking socialisation is substantially more than telling children that they should not smoke. From the child's perspective, anti-smoking socialisation involves internalisation of attitudinal and behavioural norms against smoking initiation, acceptance of parental monitoring of smoking, expectations of negative consequences for trying smoking, and expectations of positive consequences for not smoking.

Exposure to adults who smoke is an important mechanism of child socialisation regarding tobacco use. ${ }^{89}$ Anti-smoking socialisation is, however, multifaceted and is therefore an option for parents who smoke. Parents who smoke can talk to children about smoking, counter pro-smoking influence from media and peers, monitor the smoking behaviour of children and their friends, make clear the disciplinary consequences of smoking, reinforce children for staying smoke-free, and reduce children's exposure to tobacco smoke. Of interest in the present study was whether the Smoke-free Kids programme could engage parents who smoke in these activities and whether such engagement would alter children's susceptibility to smoking.

A criticism regarding the potential efficacy of anti-smoking socialisation is that most children have a negative perception of smoking. Indeed, most children would agree that smoking is a "bad" thing to do. However, children can agree with a negative statement about smoking and still be cognitively 
predisposed to smoke. This discrepancy could occur because individuals typically do not hold uniformly negative or positive beliefs and evaluations, but rather a blend of positive and negative beliefs and evaluations about a single object, such as smoking. ${ }^{10}$ The relative number and salience of proversus anti-smoking beliefs and evaluations determines the normative position of a child with regard to smoking. A normative position will be strongly negative only when underlying beliefs and values are predominantly antismoking. Thus, because children will agree that "smoking is bad" does not mean that they are not simultaneously being socialised to adopt multiple pro-smoking beliefs and evaluations that could comprise a predominantly pro-smoking norm.

\section{Anti-smoking socialisation and children's risk of smoking}

Non-intervention studies have been conducted which indicate that anti-smoking socialisation is associated with lower risk of smoking. ${ }^{411-14}$ In a longitudinal study of 182 motheroffspring pairs, Chassin et al found that offspring exposed to smoking specific discussion and punishment were significantly less likely to take up smoking. ${ }^{13}$ In a cross sectional study of 1213 third and fifth grade children, Jackson and Henriksen $^{4}$ found that anti-smoking socialisation was associated with significantly lower odds of smoking initiation. More recently, Sargent and colleagues ${ }^{14}$ found that adolescents who perceived strong parental disapproval of smoking at baseline were less than half as likely to report established smoking at follow up.

Few studies have examined parents who smoke as sources of anti-smoking socialisation. Indeed, it is widely perceived that parents who smoke can do little to dissuade their children from smoking. Yet studies indicate that a protective effect is possible. ${ }^{45^{13}{ }^{14}}$ In one analysis restricted to households with at least one parent who smoked, strong associations were found between anti-smoking socialisation and the likelihood that elementary school children had ever tried smoking. ${ }^{4}$ This study found, for example, that $16 \%$ of children who believed their parents would know if they were smoking reported initiation, versus $50 \%$ of children who believed their parents would not know (relative risk (RR) 3.6; p < 0.05); $20 \%$ of children who expected negative consequences for trying smoking reported initiation, versus $58 \%$ of children without this expectation (RR 4.9; $\mathrm{p}<0.05){ }^{4}$

\section{Barriers to anti-smoking socialisation}

Although the available studies indicate that anti-smoking socialisation can be protective, relatively few parents are engaged in these activities, ${ }^{5-7}$ and parents who smoke are engaged least of all. ${ }^{5}$ One general barrier to anti-smoking socialisation is parental complacency due to the belief that cigarette smoking is a problem of adolescence. Importantly, parental complacency is not devoid of a socialising effect. As posited by Baumrind and Moselle, ${ }^{15}$ children commonly interpret parental passivity as tacit approval or lack of disapproval. Parental complacency is particularly damaging if parents are smokers because, without exposure to parental anti-smoking attitudes, offspring are left to derive their beliefs about smoking from parental smoking behaviour. ${ }^{12}$

Another barrier, unique to parents who smoke, is perceived hypocrisy. Not surprisingly, parents who smoke believe that they lack credibility as sources of anti-smoking messages for their children. ${ }^{7}$ This belief is strongly held by parents who smoke and must be overcome by any programme that aims to involve adult smokers in anti-smoking socialisation with children.

\section{Summary and hypotheses}

In the wake of evidence indicating that school based programmes are insufficient to prevent youth smoking, ${ }^{16-18}$ investigators are giving increased attention to understanding parental involvement in smoking prevention. The present study evaluated the effects of a programme designed to increase anti-smoking socialisation in households where parents smoke cigarettes. Two hypotheses were tested:

(1) the programme would affect significant increases in parental reports of anti-smoking socialisation three months post-intervention

(2) the programme would have significant beneficial effects on multiple indicators of children's susceptibility to smoking two years post-baseline.

Health promotion programmes should be evaluated using multiple research strategies; two principal strategies are programme efficacy research, and programme effectiveness research. ${ }^{19}$ Efficacy research tests programmes under optimal conditions, when programme availability and acceptance are maximised; effectiveness research tests programmes under real world field conditions, when programme availability and acceptance vary. ${ }^{19}$ Because this was the first evaluation of an innovative approach to smoking prevention, and given the need to learn as much as possible from the evaluation, both programme efficacy and programme effectiveness strategies were used to test the study hypotheses.

\section{METHOD}

\section{Recruitment and sample}

Given the voluntary nature of participation in a home based smoking prevention programme, selection bias would have diminished the random quality of an attempted probability sample. A non-probability method was therefore used that entailed enrolling and verifying the eligibility of potential participants.

For two consecutive academic years, administrators of 28 school districts allowed project staff to request that school principals disseminate institutional review board (IRB) approved recruitment materials (cover; consent form; tracking form) via third grade classrooms. These districts were located in North Carolina, South Carolina, and Colorado, with 15, 3 , and 10 school districts per state, respectively. Materials were mailed to elementary school principals with a cover letter that documented district cooperation. Principals were asked to distribute the materials to third grade teachers with the request that they send the materials home with students. Interested parents could enrol in the study by mailing a signed consent form to a project office at the university. The role of school districts in this study was limited to dissemination of recruitment materials.

The eligibility of those submitting consent forms was verified at baseline, before randomisation. Eligible respondents were parents or guardians who reported current smoking at baseline and had a child who was enrolled in the third grade (ages 7-8 years) and who had not tried smoking. Of the 887 parents and children who met these criteria, completed the baseline measures, and were randomised to condition $(\mathrm{n}=44 \mathrm{l}$ treatment; $\mathrm{n}=446$ control), 746 parents $(84 \%)$ completed the three month post-intervention interview and, of these, 671 children ( $76 \%$ of $887 ; 90 \%$ of 746 ) completed the two year post-baseline interview. The present study used data from these 671 parents and children $(n=327$ treatment; $\mathrm{n}=344$ controls) (fig 1). The demographic profile of the sample and results of the analyses for attrition bias are presented under results.

This voluntary recruitment method precluded obtaining an estimate of the response rate among eligible persons (that is, number self enrolled/total number eligible). Obtaining a valid estimate of the denominator would have required a separate, probability based survey that measured the rate of smoking among parents and guardians of third graders in districts where recruitment occurred. In addition, any estimate of the 


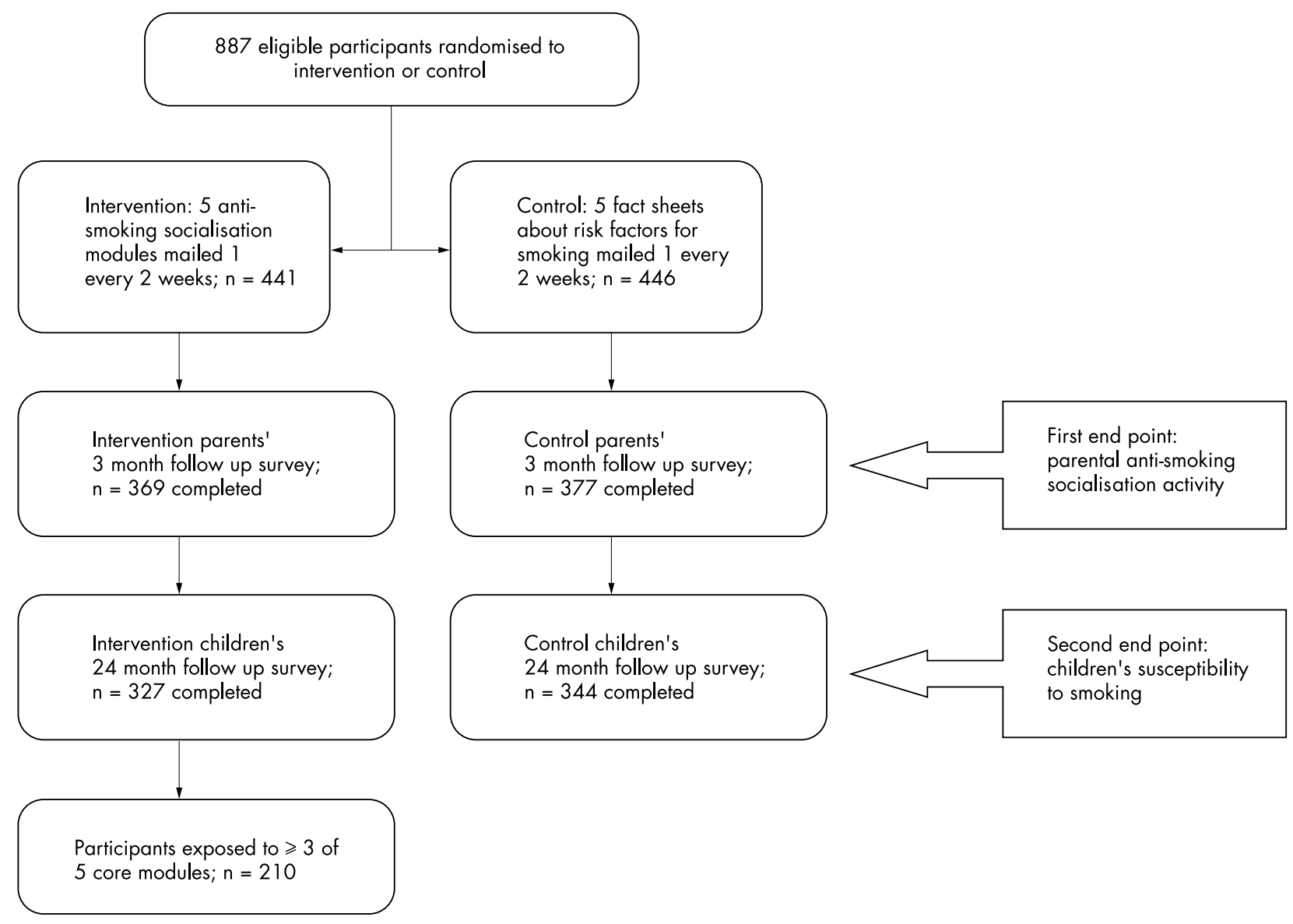

Figure 1 Study design and specification of the subgroups compared to evaluate programme effectiveness and programme efficacy. This study used the 671 cases with complete parent and child data. For each end point, programme effectiveness was evaluated by comparing cases assigned to intervention $(n=327)$ with controls $(n=344)$. Also for each end point, programme efficacy was evaluated by comparing cases exposed to $\geqslant 3$ modules $(n=210)$ with controls $(n=344)$.

denominator would have to be adjusted by counts of how many principals received and distributed the materials to teachers, how many teachers sent the materials home with students, how many children delivered the materials to parents, and how many parents read the materials. Obtaining these data was neither practical nor directly relevant to the study aims. Thus, this study does not generate information on the recruitability of adults who smoke into a programme of the type offered by this project.

\section{Intervention}

Parents and children in the treatment condition received five printed activity modules mailed to their homes at approximately two week intervals. Because the psychological and behavioural objectives of the modules were also the study outcomes, a list of these objectives is provided under description of the dependent variables (below) and in table 1 . Samples of the programme modules can be viewed at http://www.sph.unc.edu/smokefreekids

The modular intervention format was selected to standardise the pace of implementation and to avoid overwhelming participants with too much information at one time. In addition, the programme included several sequential elements and modular delivery allowed sequential exposure. For example, the modules gradually increased parents' skill and comfort level in communicating with their children about their personal smoking history, addiction, and expectations regarding abstinence. This sequence began with general communication skills in module 1 , moved to answering relatively easy questions about smoking in module 2, and then to answering more sensitive questions in module 3. By the time parents were asked by their children "Why should I not smoke when you do?" the programme had aimed to impart the confidence, skills, and scripts necessary to respond effectively. In addition to this sequential aspect, each module targeted multiple objectives. For example, the objectives of module 1 included increasing parental self efficacy regarding anti-smoking socialisation, decreasing parental perceptions of hypocrisy, strengthening parent-child communication skills, and engaging parents in teaching children effective decision making. Finally, the modules used repetition to reinforce or broaden the application of key socialisation objectives. For example, modules 2 and 3 addressed the issue of addiction, and modules 1, 3, and 4 targeted hypocrisy as a barrier to anti-smoking socialisation. The sequential, multicomponent, and repetitive attributes of the modules had implications for evaluation: because the modules were not discrete with regard to content, it was not possible to isolate or measure module specific effects. From a research perspective, the modules comprise a single programme to which participants could have varying levels of exposure.

In addition to the modules the intervention included a telephone call from a health educator during the course of the programme to provide parents with support and motivation; a toll-free number that parents were encouraged to use at any time; a series of parent newsletters that allowed information exchange among parents who smoke; a series of newsletters for children that reinforced the messages children received from parents and provided children with a large non-smoking referent group; incentives (for example, picture frames, yo-yos) that were given to all participants to thank them for 
Table 1 Parental reports of anti-smoking socialisation three months post-intervention

\begin{tabular}{|c|c|c|c|c|c|c|c|c|c|}
\hline & \multicolumn{3}{|c|}{ Evaluation groups* } & \multicolumn{6}{|c|}{ Evaluation strategy } \\
\hline & \multirow{2}{*}{$\begin{array}{l}\text { Assigned } \\
(n=327) \\
\end{array}$} & \multirow{3}{*}{$\begin{array}{l}\text { Exposed } \\
(n=210) \\
\% y e s\end{array}$} & \multirow{3}{*}{$\begin{array}{l}\text { Control } \\
(n=344) \\
\% y e s\end{array}$} & \multicolumn{3}{|c|}{ Efficacy evaluation $\dagger$} & \multicolumn{3}{|c|}{ Effectiveness evaluationł } \\
\hline & & & & \multicolumn{3}{|c|}{ Exposed $v$ control } & \multicolumn{3}{|c|}{ Assigned $v$ control } \\
\hline & \%yes & & & OR§ & $95 \% \mathrm{Cl}$ & $\mathrm{p}$ Value & OR & $95 \% \mathrm{Cl}$ & $\mathrm{p}$ Value \\
\hline \multicolumn{10}{|l|}{ Gain self efficacy to prevent smoking } \\
\hline Smokers can do a lot to prevent smoking & 91.3 & 93.2 & 86.7 & 2.29 & (1.20 to 4.34 ) & 0.01 & 1.78 & $(1.06$ to 2.95$)$ & .02 \\
\hline $\begin{array}{l}\text { Would know if child has tried smoking } \\
\text { Disclose smoking experience }\end{array}$ & 79.1 & 81.3 & 69.1 & 1.84 & $(1.21$ to 2.18$)$ & 0.00 & 1.60 & (1.12 to 2.27$)$ & .01 \\
\hline Parent explains own smoking history & 72.3 & 75.1 & 64.7 & 1.66 & (1.11 to 2.45$)$ & 0.01 & 1.46 & (1.04 to 2.04 ) & .02 \\
\hline Parent describes addiction to tobacco & 87.8 & 91.4 & 86.0 & 1.77 & (1.02 to 2.88$)$ & 0.05 & 1.28 & (0.93 to 1.74 ) & .30 \\
\hline \multicolumn{10}{|l|}{ Communicate negative consequences } \\
\hline Explain negative consequences to child & 64.7 & 71.3 & 53.9 & 2.03 & (1.39 to 2.95$)$ & 0.00 & 1.49 & (1.08 to 2.03 ) & .01 \\
\hline Make own negative attitude explicit & 86.2 & 88.0 & 81.4 & 1.77 & (1.08 to 2.93 ) & 0.02 & 1.50 & (0.99 to 2.26$)$ & .06 \\
\hline \multicolumn{10}{|l|}{ Reinforce smoke-free status } \\
\hline Reward child for being smoke-free & 23.7 & 30.6 & 12.8 & 2.77 & (1.78 to 4.29 ) & 0.00 & 1.95 & (1.29 to 2.93 ) & .00 \\
\hline \multicolumn{9}{|l|}{ Teach child media literacy } & .00 \\
\hline Debunk tobacco print advertisements & 71.2 & 80.5 & 49.7 & 4.26 & (2.82 to 6.41$)$ & 0.00 & 2.58 & (1.88 to 3.53$)$ & .00 \\
\hline Discuss smoking by actors, performers & 52.5 & 62.4 & 33.4 & 3.15 & (2.18 to 4.52$)$ & 0.00 & 2.10 & (1.53 to 2.87 ) & .00 \\
\hline \multicolumn{10}{|l|}{ Prepare child to respond to peers } \\
\hline Explain actual $v$ perceived prevalence & 46.5 & 54.8 & 40.7 & 1.72 & (1.19 to 2.44$)$ & 0.00 & 1.26 & $(0.91$ to 1.72$)$ & .15 \\
\hline \multirow{2}{*}{\multicolumn{10}{|c|}{ Monitor smoking initiation }} \\
\hline & & & & & & & & & \\
\hline Ask if child has tried smoking & 70.2 & 74.3 & 65.7 & 1.49 & (1.10 to 2.13$)$ & 0.04 & 1.24 & $(0.88$ to 1.73$)$ & .20 \\
\hline Ask if friends have tried smoking & 64.4 & 69.0 & 60.3 & 1.47 & (1.07 to 2.13 ) & 0.04 & 1.23 & $(0.89$ to 1.68$)$ & .20 \\
\hline \multicolumn{10}{|l|}{ Reduce child's exposure to smoke } \\
\hline Parent smokes only outside the home & 29.4 & 30.4 & 28.5 & 1.10 & (0.72 to 1.65$)$ & 0.65 & 1.11 & $(0.78$ to 1.58$)$ & .56 \\
\hline \multicolumn{10}{|l|}{ Establish social contracts with child } \\
\hline Child agrees to never try smoking & 56.1 & 67.0 & 39.5 & 3.15 & (2.18 to 4.54$)$ & 0.00 & 2.01 & $(1.50$ to 2.70$)$ & .00 \\
\hline Child agrees to tell if friends smoke & 68.2 & 72.9 & 59.2 & 1.78 & (1.21 to 2.61$)$ & 0.00 & 1.45 & (1.06 to 1.98 ) & .02 \\
\hline
\end{tabular}

participating and to encourage submissions to the newsletters; other incentives donated by local merchants (for example, children's camera, backpack) that were used as prizes in programme contests; and finally, a booster module delivered one year post-baseline which had as its theme staying smoke-free one year at a time.

A fact based programme was developed for families in the control condition. Providing an alternative programme for controls was done principally because pilot work indicated the need to establish a plausible explanation for the follow up interviews with parents and children in the control condition. The fact sheets provided knowledge about youth smoking and focused parents' attention on macro-level variables relevant to youth smoking but not targeted by the treatment version of the programme (for example, cost of cigarettes, sales of tobacco to minors). The criterion for selecting information for the fact sheets was that the same information was available in local, state, or national print or broadcast media. Although the information provided could increase control group parents' knowledge regarding tobacco issues, this awareness was not expected to affect anti-smoking socialisation processes. The fact sheets were mailed to families in the control condition, one each time a programme module was sent to families in the treatment condition.

\section{Measures}

Eligibility status at baseline

Parents were counted as eligible smokers if they reported: (1) lifetime smoking of 100 cigarettes or more; and (2) smoking at least one cigarette per week in the presence of their child at baseline. Children were counted as eligible never smokers if they reported having never puffed on a cigarette. This widely used measure of initiation was selected based on a reliability study of elementary school children's self reported initiation of smoking. ${ }^{20}$ Children's over-time consistency was evaluated by looking for logic errors between baseline and one year follow up. Nearly all children (98\%) provided reliable reports of "ever smoking, even one puff" over one year. These and other analyses reported in this study ${ }^{20}$ corroborate the results of another reliability study, ${ }^{21}$ which found that youth are highly consistent over time in their reporting of smoking behaviour.

\section{Independent variables}

Two variables were used to indicate participants' status with regard to programme exposure.

(1) For the analyses of programme efficacy, a categorical variable designated membership in an "adequate treatment" group $(\mathrm{n}=210)$ or control group $(\mathrm{n}=344)$. Whether adequate treatment occurred was determined at post-test, when parents in the treatment condition were asked how many of the five core modules were delivered and used. The distribution of responses for the use of $0,1,2,3,4$ or 5 modules was $12.5 \%, 8.6 \%, 14.7 \%, 32.1 \%, 18.0 \%$, and $14.1 \%$, respectively. Those who reported use of at least three of the core modules were designated as having adequate treatment $(\mathrm{n}=210$ or $64.2 \%$ of parents randomised to treatment). The attrition analyses included a comparison of the participants with adequate versus less than adequate treatment.

(2) For the analyses of programme effectiveness, a categorical variable indicated randomisation to the treatment $(\mathrm{n}=327)$ or control $(\mathrm{n}=344)$ group.

\section{Covariates}

Predictors used as control variables in the analyses of programme efficacy and effectiveness were child's sex, 
parent's sex, parent's level of education (high school or equivalent $v$ some college or higher), and parent's race (white $v$ non-white). In addition, preliminary analyses to determine group equivalence at baseline indicated that parents in the adequate treatment group $(\mathrm{n}=210)$ were significantly more likely than controls $(\mathrm{n}=344)$ to report telling children they would be proud of them for not smoking (odds ratio 1.78; $p=0.03)$. The baseline measure of this variable was therefore used as a covariate when programme effects on this outcome were analysed.

\section{Dependent variables}

Anti-smoking socialisation effects were measured on the parent survey in the following categories: (1) parental self efficacy regarding smoking prevention; (2) parental self disclosure of smoking history and experience with addiction; (3) parental explication of negative consequences for initiation of smoking; (4) parental reinforcement of child's abstinence; (5) effort by parent to counter pro-smoking influence from media; (6) effort by parent to counter pro-smoking influence from peers; (7) parental monitoring of smoking initiation by children and friends; (8) parental effort to reduce child's exposure to tobacco smoke in the home; (9) parental action to establish social contracts against smoking with children. As shown in table 1, two indicators were used to assess each type of anti-smoking socialisation.

Among abstinent youth, susceptibility to smoking can be indicated by psychological, behavioural, and situational attributes that discriminate between youth who will remain abstinent and youth who will initiate smoking. ${ }^{22-24}$ At the 24 month follow up the child interview measured attributes of abstinent children that can reduce susceptibility: (1) having a parent who is perceived by the child as wanting to communicate about smoking, indicated by a child's report of whether a parent "likes to talk with me about smoking"; (2) involvement in a social contract that establishes a promise or agreement with a parent to avoid smoking; (3) holding the belief that smoking activity will be detected by a parent; (4) holding the belief that abstinence will be rewarded by a parent. Also measured were attributes of abstinent children that can raise susceptibility: (1) intention to smoke when older; and (2) exposure to at least one best friend who has initiated smoking.

\section{Survey protocol}

Telephone interview data were obtained from parents and children. In the baseline year, during which both parties were interviewed, children were interviewed before parents to avoid the possibility that the parent interview would influence parental behaviour about smoking and thereby influence children's responses. In all instances, interviewers were blinded to study condition.

\section{Child interview}

At baseline and 24 months the children's interview was administered in-house with staff who had at least two years of experience working with children and successfully completed 30 hours of training over a two week period. The training covered ethical treatment of human subjects, reading the assent transcript, standardising the pace and modulation of reading, reading with a voice that did not give any hint of agreement or disagreement with responses, and maintaining momentum through the interview.

The child interview began by asking parents to provide verbal consent before interviewers spoke with children (this was in addition to the signed consent already obtained). This procedure included requesting that the parent "Ask your child to go sit somewhere that's quiet, let your child know that it's okay with you if he/she answers our questions about smoking, and let your child know that he/she won't have to discuss any answers after the interview ends. Please tell your child that it is okay with you if he/she sits and answers our questions privately." After providing non-binding verbal assent, children were asked by the interviewer to move to a place that was private, comfortable and without obvious distractions (for example, television). Interviewers initiated a semi-structured chat session, where topics unrelated to the interview were discussed (for example, sports, hobbies). This session helped the child and interviewer establish rapport and become accustomed to one another's voices before the interview. Once the interview began, interviewers maintained strict adherence to the script. A key feature of the interview was that the questions were structured so that the response choices did not convey any potentially sensitive information. Although completion times varied, the interview proper took about 20 minutes to complete.

\section{Parent interview}

A computer assisted parent interview was administered under contract with a campus based survey research unit. The principal investigator, project director, and coordinator of the research unit jointly trained and supervised the interviewers. At least $10 \%$ of the interviews were monitored. Parents were interviewed at a time that they indicated was convenient; interviews were rescheduled if background noise indicated that the parent was distracted or rushed.

\section{Analysis}

For attrition analysis, $\chi^{2}$ tests were used to examine the demographic comparability of enrollees retained over two years $(n=671)$ with enrollees who completed the baseline assessment but were lost to follow up $(\mathrm{n}=216) \cdot \chi^{2}$ tests were also used to compare participants who reported adequate treatment (that is, used at least three of five programme modules; $\mathrm{n}=210$ ) with those who reported less than adequate treatment (that is, used two or fewer modules; $\mathrm{n}=117$ ).

Hierarchical logistic regression was used to test the effects of the programme on anti-smoking socialisation at three months and on susceptibility to smoking at two years. For the evaluation of programme efficacy these outcomes were regressed at step 1 on the control variables (forced entry) and at step 2 on a dichotomous indicator of adequate treatment versus control status. The tests of treatment effectiveness followed the same procedure except that a dichotomous indicator of randomisation to treatment versus control condition was entered at step 2 .

\section{RESULTS}

\section{Sample}

Within the eligible sample $(\mathrm{n}=671)$ the distribution by race was $78 \%$ white, $16 \%$ African American, 1\% Hispanic, < $1 \%$ Asian or Pacific Islander, $2 \%$ Native American, and 2\% other or more than one group. The distribution by level of education was $2 \%$ eighth grade or lower, $6 \%$ some high school, $28 \%$ high school graduate or equivalent, $48 \%$ vocational or two year college, and $16 \%$ bachelors degree or higher. The distribution by employment status was $61.5 \%$ full time, $20 \%$ part time, and $18.5 \%$ not employed for pay. Parents' mean age was 36.6 years and, as occurred in the pilot study, the majority of participants $(80 \%)$ were women. All parents were current smokers, with $51 \%$ smoking less than one pack per day and $49 \%$ smoking a pack or more per day. Among the children enrolled by parents, $53 \%$ were female and all were in the second half of their third grade year in school.

\section{Attrition analyses}

Attrition analyses compared the 67l participants retained with the 216 lost to follow up. The results showed no differential attrition by study condition, parents' age, parents' level of education, parents' sex, number of cigarettes parents smoked per day, or child's sex. There was, however, differential attrition 
associated with race, such that European Americans were significantly more likely than persons of other race/ethnicity groups to complete a follow up interview $\left(\chi^{2}=11.06\right.$; $\mathrm{p}<0.001)$.

Attrition analyses were also conducted within the treatment group to test for differences between the 210 who reported adequate treatment and the 117 who did not. The results showed no differences between these groups in parents' age, parents' level of education, parents' sex, parents' race, or number of cigarettes parents smoked per day. Attrition bias was evident, however, with regard to children's sex, such that parents of girls were significantly more likely than parents of boys to report adequate treatment $\left(\chi^{2}=4.94\right.$; $\mathrm{p}<0.05)$.

\section{Effects on anti-smoking socialisation}

Evaluation of programme efficacy showed that adequate exposure predicted significant increases at the parent posttest in eight of nine categories of anti-smoking socialisation. Parents who had adequate treatment were significantly more likely than controls to believe they could prevent smoking, discuss their smoking history and addiction experience with children, express their negative attitude about children's involvement with smoking, and communicate with children regarding the disciplinary consequences of initiation and the positive consequences of abstinence (table 1). In addition, parents who had adequate treatment were significantly more likely than controls to discuss peer and media influence factors, monitor children's and friends' smoking activity, and establish social contracts against smoking initiation with their children. The programme had no effect on children's exposure to tobacco smoke, as indicated by parental reports of smoking outside the home or smoking in a designated space inside the home.

Table 1 also shows the results of the evaluation of programme effectiveness. Significant programme effects were evident for several anti-smoking socialisation outcomes, including parental self-efficacy to prevent smoking, parental reinforcement of abstinence, and parental effort to counter pro-smoking influence from media. However, the magnitude of these effects was systematically lower than the magnitude of programme efficacy effects. For example, the effectiveness results indicated that parents in the treatment group were $78 \%$ more likely than controls to believe that they "can do a lot to prevent smoking". In contrast, the efficacy results indicated that parents with adequate treatment were over twice as likely as controls to hold this belief. Similarly, the effectiveness results showed that parents randomised to treatment were more than twice as likely as controls to debunk tobacco ads or discuss smoking images in the media, whereas parents with adequate treatment were three to four times as likely as controls to engage in media-specific socialisation.

\section{Effects on children's susceptibility to smoking}

The efficacy evaluation revealed significant between-group differences in children's susceptibility to smoking two years post-baseline. Relative to controls, children exposed to adequate treatment were twice as likely to perceive that their parents liked to talk with them about smoking, 54\% more likely to report having a social contract against smoking, 84\% more likely to believe that parents would detect smoking, and $55 \%$ more likely to expect abstinence to be rewarded. The efficacy evaluation also showed that children in the control group had significantly higher scores than children exposed to the programme on attributes that increase susceptibility-that is, children in the control group were $85 \%$ more likely to intend to smoke in adolescence and twice as likely to have a best friend who had initiated smoking.

The programme effectiveness evaluation indicated that children randomised to treatment had higher levels of the attributes that lower susceptibility and that children in the control group had higher levels of the attributes that raise susceptibility, but several of the between-group differences were not significant (table 2). Children in the treatment group were significantly more likely than controls to perceive that parents liked to talk about smoking and significantly more likely to expect abstinence to be rewarded; they also were significantly less likely than controls to intend to smoke in adolescence. Although children in the treatment group were 30\% more likely than controls to have a social contract against smoking, 36\% more likely to believe a parent would detect smoking, and $37 \%$ less likely to have a friend who had initiated smoking, these differences were not significant.

\section{DISCUSSION}

Children are socialised to smoke before they puff on a cigarette. This premise of the socialisation model of smoking adoption defines socialisation not as mastery of the mechanics of smoking, but as internalisation of social norms that favour smoking. The goal of the Smoke-free Kids programme was to modify processes of smoking specific socialisation of abstinent children so that a predominantly anti-smoking norm was achieved. The programme aimed to do this by engaging parents who smoke as agents of anti-smoking socialisation.

Table 2 Indicators of susceptibility to smoking among children two years post-baseline

\begin{tabular}{|c|c|c|c|c|c|c|c|c|c|}
\hline & \multicolumn{3}{|c|}{ Evaluation groups* } & \multicolumn{6}{|c|}{ Evaluation strategy } \\
\hline & \multirow{3}{*}{$\begin{array}{l}\text { Assigned } \\
(n=327) \\
\% \text { yes }\end{array}$} & \multirow{3}{*}{$\begin{array}{l}\text { Exposed } \\
(n=210) \\
\% \text { yes }\end{array}$} & \multirow{3}{*}{$\begin{array}{l}\text { Control } \\
(n=344) \\
\% \text { yes }\end{array}$} & \multicolumn{3}{|c|}{ Efficacy evaluation $\dagger$} & \multicolumn{3}{|c|}{ Effectiveness evaluation $\ddagger$} \\
\hline & & & & \multicolumn{3}{|c|}{ Exposed $v$ control } & \multicolumn{3}{|c|}{ Assigned $v$ control } \\
\hline & & & & ORß & $95 \% \mathrm{Cl}$ & $\mathrm{p}$ Value & OR & $95 \% \mathrm{Cl}$ & $\mathrm{p}$ Value \\
\hline \multicolumn{10}{|l|}{ Child attributes that reduce susceptibility } \\
\hline Believes parent likes to talk about smoking & 51.7 & 59.3 & 41.6 & 2.09 & (1.44 to 3.02$)$ & 0.00 & 1.52 & $(1.10$ to 2.10$)$ & 0.01 \\
\hline Affirms having social contract with parent & 73.8 & 77.3 & 68.2 & 1.54 & $(1.03$ to 2.31$)$ & 0.03 & 1.30 & $(0.92$ to 1.83$)$ & 0.13 \\
\hline Believes parent would detect smoking & 84.4 & 88.3 & 80.5 & 1.84 & (1.10 to 3.06$)$ & 0.01 & 1.36 & (0.89 to 2.04$)$ & 0.14 \\
\hline Expects parent will reward abstinence & 36.4 & 38.6 & 28.2 & 1.55 & (1.06 to 2.25$)$ & 0.02 & 1.41 & (1.01 to 1.98$)$ & 0.04 \\
\hline \multicolumn{10}{|l|}{ Child attributes that raise susceptibility } \\
\hline Intends to smoke in adolescence & 10.4 & 8.5 & 16.1 & 0.54 & $(0.31$ to 0.95$)$ & 0.03 & 0.60 & $(0.37$ to 0.95$)$ & 0.03 \\
\hline Has a best friend who has smoked & 25.3 & 19.2 & 30.8 & 0.49 & $(0.32$ to 0.76$)$ & 0.00 & 0.73 & $(0.52$ to 1.03$)$ & 0.07 \\
\hline
\end{tabular}

*Random assignment placed 327 participants in the treatment group; of these, 210 were exposed to $\geqslant 3$ of 5 core program modules

tThe efficacy evaluation compared parents who reported exposure to $\geqslant 3$ modules $(n=210)$ with controls $(n=344)$.

$\ddagger$ The effectiveness evaluation compared parents randomly assigned to treatment $(n=327)$ with controls $(n=344)$.

$\S$ Odds ratios adjusted for child's sex, parent's sex, parent's education, and parent's race. 
Given the innovative aspect of Smoke-free Kids, two methods were used to evaluate the programme. First, efficacy was evaluated by measuring the effects achieved when the availability and acceptance of the programme were maximised ${ }^{19}$ The results provided generally strong support for the study hypotheses. Parental anti-smoking socialisation increased significantly at follow up in all but one category of socialisation. Particularly noteworthy was the significant increase in parental confidence to prevent children from smoking. This result suggests that the programme reduced the perceived hypocrisy that occurs when adult smokers contemplate involvement in anti-smoking socialisation. This was a key programme objective because of the inhibiting effect of this perception on parental involvement in smoking prevention. Equally noteworthy was the significant increase in social contracts against smoking made between parents and children. Although clinician instigated contracts to promote general parent-child communication about tobacco use and other issues were found to be ineffective, ${ }^{25}$ a social contract that targets an explicit interpersonal commitment is known to be a strong motivational factor, such that individuals generally resist violating intentions expressed during establishment of such contracts. ${ }^{26}$ To the extent that this motivation was instilled and reinforced by parents, children should be less likely to initiate smoking.

Other programme effects complemented the reported increases in parental confidence to prevent smoking and children's social commitment against smoking. These complementary effects included significant increases in parent-child communication about peer and media influences, in parental monitoring of smoking by children and friends, in parental specification of the disciplinary consequences of initiation, and in parental use of reinforcement to strengthen children's abstinence from smoking. Overall, these results support the conclusion that under the condition of adequate treatment, the Smoke-free Kids programme affected significant increases in anti-smoking socialisation in households where parents smoke.

The efficacy evaluation also supported the second study hypothesis: two years after baseline, the programme had beneficial effects on children's susceptibility to smoking. Programme exposure significantly increased children's perception that their parents were willing communicators regarding smoking. This improvement provides indirect evidence of a sustained effect of the programme on parental confidence to be a voice against smoking, and it provides direct evidence that children exposed to the programme had greater access than controls to a parent who remained motivated to prevent smoking.

Programme exposure also had significant positive effects on children's perceptions of having a social contract with a parent against smoking, on perceived parental capacity to detect smoking, and on the expectation that abstinence will be rewarded. These reports from children were collected 18 months after parental reports of similarly measured outcomes. Thus, the efficacy results obtained from children corroborated the results obtained from the earlier parent interviews. Moreover, the data from children showed that the programme had a sustained effect on key parenting practices associated with smoking prevention.

The programme also had significant negative effects on the then fifth graders' intentions to smoke when older and on their having a friend who had initiated smoking. In another study that tracked children from grades 5 to 7 , these susceptibility factors were found predict initiation of smoking. ${ }^{24}$ Overall, the programme efficacy evaluation supports the conclusion that given adequate exposure, the Smoke-free Kids programme had beneficial effects on children's susceptibility to smoking two years post-baseline.

The second method used to evaluate the programme was treatment effectiveness analysis, where all participants ran-

\section{What this paper adds}

In the wake of evidence indicating that school based programmes are insufficient to prevent smoking, attention has turned to the role of parents in preventing children from smoking. Past studies have found that anti-smoking socialisation by parents predicted lower rates of smoking among offspring. However, relatively few parents engage in antismoking socialisation, and parents who smoke engage least of all.

This trial evaluated an anti-smoking socialisation programme designed specifically for parents who smoke. This is the first programme of its kind. The evaluation found that parents who smoke can successfully engage in several forms of anti-smoking socialisation with their children, and that anti-smoking socialisation by parents reduced children's susceptibility to smoking over a two year period. These findings suggest that parents who smoke have a critical role to play in curtailing the inter-generational transmission of smoking.

domised to the treatment condition were compared with controls. These analyses indicated the utility of the programme when availability and acceptance vary. ${ }^{19}$ The results showed that the programme had modest effects when tested under these conditions. Although all of the between-group differences in the indicators of anti-smoking socialisation and susceptibility to smoking were in the hypothesised direction, approximately half of these differences were not significant. In contrast, nearly all parent and child indicators of programme effect were significantly different in the evaluation of programme efficacy.

The contrasting results of the efficacy and effectiveness evaluations point to the need to develop strategies that will enhance programme availability and acceptability. It is possible that alternative formats (for example, an interactive multimedia version of the programme) or alternative delivery methods (for example, smaller programme doses delivered at longer intervals) would improve acceptability to parents. It is also possible that alternative incentives would boost participation rates. For example, monetary incentives used at intervals might help to sustain participation over time. Efforts to develop alternative strategies should also consider that this study found higher attrition among parents of boys than among parents of girls. It is plausible that the teaching tools used in the programme modules (for example, communication games, art and writing contests) or the print format of the modules appealed more to girls than boys, and thereby affected the differential participation by sex. These and other modifications, including improving the programme's capacity to attract and maintain involvement by adult smokers, would be necessary before treatment effectiveness can be demonstrated.

It is clear that the results of this study can be generalised only to adult smokers who are receptive to the opportunity to engage in anti-smoking socialisation. The generalisability of the results is also limited because European Americans were significantly more likely to complete the follow up interviews than persons from other race/ethnicity groups. Bauman et al similarly found that participation in a family directed tobacco and alcohol prevention programme for teens was most likely among non-Hispanic whites when compared with persons from other race/ethnicity groups. ${ }^{27}$ Lacking post-intervention data from those lost to follow up, we cannot speculate whether higher attrition among them was due to attributes of the programme, the data collection procedures, or other factors. Additional work is needed to understand variation by ethnicity in the acceptability and utility of this home based, self help approach to smoking prevention. 
Another limitation of the present study is the lack of information on the reliability and validity of parental reports of anti-smoking socialisation activities. It is likely that social desirability leads parents to over report these activities; indeed, the relatively high rates of activity reported by control parents suggest that this is the case. Although such over reporting would exert a conservative effect on the results of the present study, it is important that future work undertake to evaluate the psychometric properties of these and similar measures.

The present study also lacks a behavioural end point. Because of the grade of the cohort at baseline (third grade), it is necessary to wait at least three years (until sixth grade) before the programme could have a detectable behavioural effect. That is, smoking initiation can be expected to rise upon entry into middle school, ${ }^{28}{ }^{29}$ and it is at this point that a differential effect could be detected. Collection of these follow up data on initiation of smoking is underway.

\section{Conclusion}

Within the field of tobacco control there is growing interest in engaging parents to reduce youth smoking. In 1998, the Centers for Disease Control and Prevention, with other federal agencies, sponsored a consensus conference that broke new ground by focusing on parenting as a public health issue. The aims of this conference, titled "Scientific foundations for parenting: preventing youth tobacco use and substance abuse", were to delineate parenting practices that can be risk or protective factors for youth tobacco use and to determine effective parenting interventions for prevention (written communication, July 1998). More recently, Califano and colleagues at the National Center on Addiction and Substance Abuse have argued that "Parent power is the most underutilised tool in combating substance abuse. The family is fundamental to keeping children away from tobacco, alcohol, and illegal drugs". ${ }^{30}$ National media campaigns further indicate increased effort to involve parents in prevention. For example, a theme of the mass media campaign developed by the Office of National Drug Control Policy is "Parents: the anti-drug". Providing resources on effective parenting practices is a key element of this campaign. ${ }^{31}$

At present, the capacity of parents to prevent their children from smoking is relatively untested. The Smoke-free Kids study was undertaken to test one approach to enabling parents to reduce their children's risk of addiction to tobacco. This programme is unique because it is the first anti-smoking socialisation programme for parents of young children and because it is designed for parents who smoke. The results of this research indicate that the programme has the potential to increase anti-smoking socialisation at home and to reduce children's susceptibility to smoking over a two year period.

Research is underway to evaluate the programme's potential to lower children's risk of smoking initiation.

\section{ACKNOWLEDGEMENT}

Support was provided by National Institute for Child Health and Human Development, grant HD36514.

\section{Authors' affiliations}

C Jackson, D Dickinson, Department of Health Behavior \& Health Education, School of Public Health, University of North Carolina at Chapel Hill, Chapel, North Carolina, USA

\section{REFERENCES}

1 Maccoby EE, Martin JA. Socialization in the context of the family: Parent-child interaction. In: Hetherington EM, ed. Socialization, personality, and social development. New York: John Wiley; 1983:1-101.
2 Hartup WW. Peer relations. In: Hetherington EM, ed. Socialization, personality, and social development. New York: John Wiley \& Sons; 1983:116-73

3 O'Keefe GJ, Reid-Nash K. Socializing functions. In: Chafee S, Berger C eds. Handbook of communication science. Newbury Park, California: Sage; 1987:419-45

4 Jackson C, Henriksen L. Do as I say: parent smoking, anti-smoking socialization, and smoking onset among children. Addictive Behaviors 1997;21:1-8.

5 Henriksen L, Jackson C. Antismoking socialization: relationship to parent and child smoking status. Health Communication 1998; 10:87-101.

6 Fearnow M, Chassin L, Presson CC, et al. Determinants of parental attempts to deter their children's cigarette smoking. J Applied Developmental Psychol 1998;19:453-68

7 Clark PI, Scarisbrick-Hauser A, Gautam SP, et al. Anti-tobacco socialization in homes of African-American and white parents, and smoking and nonsmoking parents. J Adolesc Health 1999;24:329-39.

8 Chassin L, Presson CC, Sherman SJ, et al. Predicting the onset of cigarette smoking in adolescents: a longitudinal study. J Applied Soc Psychol 1984;14:224-43.

9 Kandel D, Wu P. The contributions of mothers and fathers to the intergenerational transmission of cigarette smoking in adolescence. J Res Adolesc 1995;5:225-52.

10 Sears DO, Freedman JL, Peplau LA. Defining attitudes. In: Sears DO, Freedman JL, Peplau LA, eds. Social psychology. New Jersey: Prentice Hall; 1985: 132-48

11 Distefan JM, Gilpin EA, Choi WS, et al. Parental influences predict adolescent smoking in the United States, 1989-1993. J Adolesc Health 1998;22:466-74.

12 Chassin L, Presson CC, Rose JS, et al. Maternal socialization of adolescent smoking: intergenerational transmission of smoking-related beliefs. Psychol Addictive Behav 1998;12:206-16.

13 Chassin L, Presson CC, Todd M, et al. Maternal socialization of adolescent smoking: the intergenerational transmission of parenting and smoking. Developmental Psychology 1998;34:1 189-201.

14 Sargent JD, Dalton M. Does parental disapproval of smoking prevent adolescents from becoming established smokers? Pediatrics 2001; 108:1256-62.

15 Baumrind D, Moselle KA. A developmental perspective on adolescent drug abuse. Adv Alcohol Substance Abuse 1985;4:41-67.

16 Vartiainen E, Pallonen $U, M c A l i s t e r ~ A L$, et al. Eight-year follow-up results of an adolescent smoking prevention program: the North Karelia youth project. Am J Public Health 1990;80:78-9.

17 Ellickson PL, Bell RM, McGuigan K. Preventing adolescent drug use: Long-term results of a junior high program. Am J Public Health 1993;83:856-61

18 Peterson AV, Kealey KA, Mann SL, et al. Hutchinson smoking prevention project: long-term randomized trial in school-based tobacco use prevention - results on smoking. J Ntl Cancer Inst 2000;92:1979-91.

19 Flay BR. Efficacy and effectiveness trials and other phases of research in the development of health promotion programs. Prev Med 1986; 15:451-74

20 Henriksen L, Jackson C. Reliability of children's self-reported cigarette smoking. Addictive Behaviors 1999;24:271-7.

21 Brener ND, Collins JL, Kann L, et al. Reliability of the youth risk behavior survey questionnaire. Am J Epidemiol 1995;141:575-80.

22 Altman DG, Levine DW, Coeytaux R, et al. Tobacco promotion and susceptibility to tobacco use among adolescents aged 12 through 17 years in a nationally representative sample. Am J Public Health 1996;86:1590-3.

23 Pierce JP, Choi WS, Gilpin EA, et al. Validation of susceptibility as a predictor of which adolescents take up smoking in the United States. Health Psychol 1996;15:355-61.

24 Jackson C. Cognitive susceptibility to smoking and initiation of smoking during childhood: a longitudinal study. Prev Med 1998;27:129-34.

25 Stevens MM, Olson AL, Gaffney CA, et al. A pediatric, practice-based randomized trial of drinking and smoking prevention and bicycle helmet gun, and seatbelt safety promotion. Pediatrics 2002;109:490-7.

26 Smith MJ. Persuasion and human action: a review and critique of social influence theories. Belmont, California: Wadsworth, 1982.

27 Bauman KE, Ennett ST, Foshee VA, et al. Correlates of participation in a family-directed tobacco and alcohol prevention program for adolescents. Health Education \& Behavior 2001;28:440-61

28 Centers for Disease Control. Tobacco use among middle and high school students - United States, 1999. MMWR Morb Mortal Wkly Rep 2000:49:49-53.

29 Johnston L, O'Malley P, Bachman J. Monitoring the future: national results on adolescent drug use, overview of key findings. Accessed July 2001. URL: http://monitoringthefuture.org/pubs/overview2000

30 National Center on Addiction and Substance Abuse. National survey of American attitudes on substance abuse VI: teens. Accessed March 2002. URL: http://casacolumbia.org

31 Office of National Drug Control Policy. National youth anti-drug media campaign. Accessed March 2002. URL: http:// www.mediacampaign.org 